\title{
THE INFLUENCE OF COVID-19 LOCKDOWN ON BTEX LEVEL DISTRIBUTIONS IN BELGRADE
}

\author{
Nataša Bukumirićc, ${ }^{2 *}$ \\ Mirjana Perišić2,3, \\ Svetlana Stanišić2, \\ Gordana Jovanović2,3, \\ Andreja Stojić, 2,3
}

${ }^{1}$ Academy of Technical Vocational study, Belgrade, Serbia

${ }^{2}$ Singidunum University,

Belgrade, Serbia

${ }^{3}$ Institute of Physics Belgrade, National Institute of the Republic of Serbia, Belgrade, Serbia

\begin{abstract}
:
In this study, we have used the Standard Proton Transfer Reaction Mass Spectrometer (PTR-quad-MS) for online measurements of volatile organic compounds during the three-month campaign before, during, and after the state of emergency introduced as a preventive measure to the COVID-19 pandemic. The obtained data were analyzed by using correlations with hierarchical clustering, box plots, time variations, and bivariate polar plots with correlation and slope factor analysis, to provide better insight into the behavior and sources of the analyzed pollutants. As shown, pollutant concentrations have decreased only a week after the introduction of the curfew, and the benzene concentration dynamic was shown to be different compared to toluene, ethylbenzene, and xylenes behavior pattern.
\end{abstract}

Keywords:

Air Quality, BTEX, COVID-19, Lockdown, PTR-MS.

\section{INTRODUCTION}

In Spring 2020, the lockdown was implemented in many countries worldwide to prevent person-to-person SARS-CoV-2 virus transmission. During that period several studies have been performed in different countries to investigate the impact of prevention measures and restrictions on air quality.

The study of Jephcote et al. [1] registered a decline in monthly average traffic counts by $69 \%$, which was reflected in the decrease of ozone, $\mathrm{NO}_{2}$, and $\mathrm{PM}_{2.5}$ concentrations by $7.6,38.3$, and $16.5 \%$, respectively. However, it has been shown that traffic had a relatively modest contribution to air quality in the UK and meteorological conditions which were associated with the observed episodes of high particulate levels confirmed the importance of long-range transport and distant emission sources. The study of Mor et al. [2] aimed at investigating the relationships between 14 pollutant concentrations and meteorological factors during the four periods of lockdown, each of them lasting for 20 days, has confirmed the impact of local residential emission sources and regional atmospheric pollutant transport on local air quality.
Correspondence:

Nataša Bukumirić

e-mail:

nbukumiric@politehnika.edu.rs 
Sari and Esen [3] used data from 61 air quality monitoring stations in 31 cities to investigate the impact of restrictions on $\mathrm{PM}_{10}$ and $\mathrm{SO}_{2}$ levels. Their results have shown that mean $\mathrm{PM}_{10}$ and $\mathrm{SO}_{2}$ levels were decreased by $38.7 \%$ and $33.9 \%$, and the observed effects of restrictions of both human and industrial activities on air quality were more pronounced than the effects of meteorological conditions.

As regards volatile organic compounds (VOCs), the study of Pakkattil et al. [4] examined the impact of lockdown on ground benzene, toluene, ethylbenzene, and xylenes (BTEX) levels in various metropolitan cities and according to the results, an enormous decline of $82 \%$ in BTEX concentrations was registered. However, despite the decline in BTEX levels and reduction of the ozone-forming BTEX potential, the corresponding decline in ozone concentrations was not observed. In the study of Kerimray et al. [5], the concentrations of PM2.5, $\mathrm{NO} 2, \mathrm{SO} 2, \mathrm{CO}$, and $\mathrm{O} 3$ were decreased by 15 to $49 \%$, however, the levels of benzene and toluene were 2-3 times higher than those registered during the previous years.

The pandemic-related measures and lockdown represented the sort of a real-world experiment that was used in many studies to derive important information and confirm conclusions that could enhance environmental policies and interventions in the future. In Serbia, preventive measures included restricted human mobility after 5 PM, during the weekend and on public holidays, except for medical personnel. Both human and industrial activities were minimized. In this study, we have investigated the impact of the most stringent introduced measures to air quality.

\section{MATERIALS AND METHODS}

The measurements of VOCs and meteorological parameters were conducted in an urban area of Belgrade, Serbia $\left(44.86^{\circ} \mathrm{N}, 20.39^{\circ} \mathrm{E}\right)$. The measurement period ( $2^{\text {nd }}$ March- $2^{\text {nd }}$ June 2020) covers two weeks before the introduction of the lockdown introduced as a response to the COVID-19 pandemic, nearly two months of curfew, and almost a month after the measures were lifted. Standard Proton Transfer Reaction Mass Spectrometer (PTR-quad-MS, Ionicon Analytik, GmbH, Austria) was used for online measurements of more than 230 masses [6], [7]. Meteorological parameters were measured using the Vaisala weather station. The calibration of PTR-MS measurements was done according to Taipale and coauthors [8] by using referent gases and a liquid calibration unit (Ionicon Analytik). The obtained data were analyzed by using correlations with hierarchical clustering, box plots, time variations, and bivariate polar plots with correlation and slope factor analysis [9]. Mobility trend reports were obtained from Google and Apple.

\section{RESULTS AND DISCUSSION}

Figure 1 shows BTEX concentrations and human activity change which were registered as a result of lockdown and curfew implemented for public safety and prevention of COVID-19 pandemic spread in Serbia.

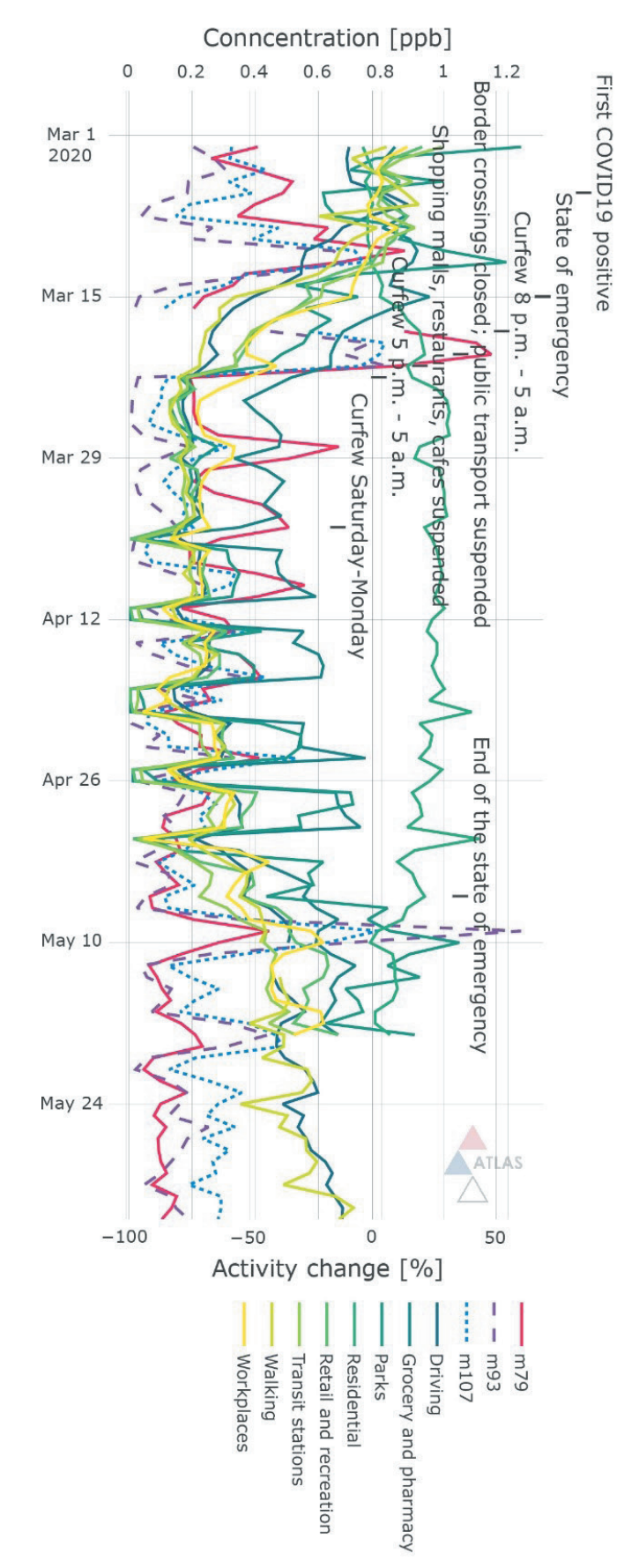

Figure 1 - BTEX concentration and human activity time series. 
As can be seen, after the lockdown introduction, pollutant concentrations did not appear to reflect instant air quality change. It is worth noting that despite the abrupt cessation of human mobility and industrial activities, the beginning of the curfew period was characterized by an increase in BTEX concentrations. It cannot be excluded that the factors i.e., unfavorable meteorological conditions and the nature of the emission sources which govern the air quality in this part of the year could be responsible for the observed BTEX dynamics.

The first significant drop in BTEX concentrations was noticed a week later after the human mobility and industrial activities were minimized. The registered declines could be related to the first curfew periods that ranged, first for 9 hours (8 p.m.-5 a.m.), then 12 (5 p.m.-5 a.m.), and finally throughout all the weekend (Saturday-Monday). After several weeks of strict measures, a certain amount of human mobility was re-introduced, but BTEX levels continued to decline. The measurement campaign ended before the intensity of human activities returned to the common level.

In the period before the introduction of lockdown, the correlation analysis shows that the compounds registered at $\mathrm{m} / \mathrm{z} 107$ (ethylbenzene and total xylene) were in good correlation with compounds at protonated masses 93 (toluene) ( $\mathrm{r}=0.93$ ) and 79 (benzene) ( $\mathrm{r}=0.9)$. This period was characterized by a good correlation between benzene and human activities such as spending time in retail and recreation $(\mathrm{r}=0.83)$ and transit stations ( $r=0.82$ ), as well as between compounds registered at $\mathrm{m} / \mathrm{z} 107$ and activities in parks $(\mathrm{r}=0.86)$ (Figure 2). Among BTEX, the linear relationship was not observed only between benzene and toluene $(\mathrm{r}=0.73)$. During the lockdown, a strong correlation was observed between all compounds of the BTEX groups, with no significant correlations between BTEX levels and human mobility. After the lockdown, the relationships between all volatiles strengthened, but the correlations with human activities were not re-established.

Figure 3 represents the changes in mean BTEX concentrations during and after restrictions relative to the period before the state of emergency. As can be seen, the decrease in BTEX levels during the lockdown was in the range of 31 to $45 \%$. The levels of volatiles increased after the human mobility and industrial activities were re-established, with exception of benzene which continued to decline up to $71 \%$ relative to the concentrations in the period before the pandemic. The box plot in Figure 4 also illustrates the decline in benzene concentrations with time. As shown, in the period after the lockdown, the $7^{\text {th }}$ percentile of benzene concentrations was only around $0.15 \mathrm{ppb}$. In this period, the traffic intensity showed a stable increase, reaching the level that was only $15 \%$ lower than before the measures (Figure 1), which is not accompanied by an increase in benzene concentrations. This suggests that the contribution of traffic emissions to the total benzene levels was overestimated in the previous literature.
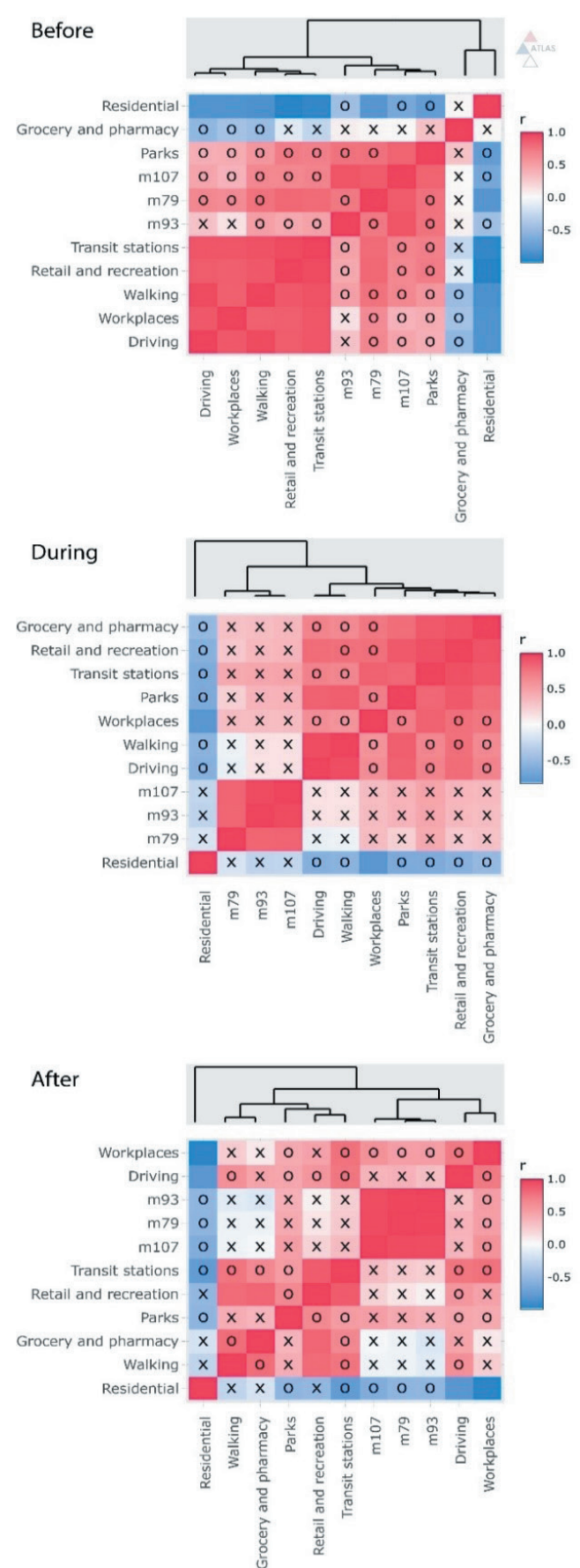

Figure 2 - Parameter value correlation matrix. 
Figure 5 shows the dependence of the correlation and slope of toluene and benzene on wind parameters. The strong relationship between these compounds before restrictions indicates the dominant emission sources. The highest correlation $(\mathrm{r}=1)$ was recorded from all wind directions in the speed range from $1 \mathrm{~m} \mathrm{~s}-1$ in the west to 8 $\mathrm{m} \mathrm{s}-1$ in the northeast from the measurement site.

The high ratio of toluene to benzene $(\mathrm{T} / \mathrm{B}$ ratio $>2)$ suggests the existence of evaporative emissions (probably from industrial activities) being located in the north, northeast, south, and southwest.

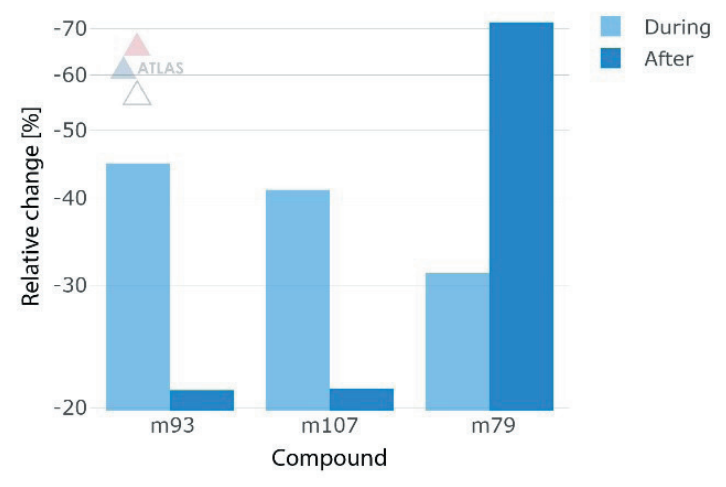

Figure 3 - Mean BTEX concentration difference during and after relative to the period before the state of emergency.

The dominance of the combustion process (T/B ratio $<2$ ) was observed during the state of emergency, while after the lockdown period, the dominant evaporative emissions were restored, mainly in the southwest direction. This may indicate the reestablishment of the industrial activities and intense evaporations supported by higher temperatures in the period May-June.

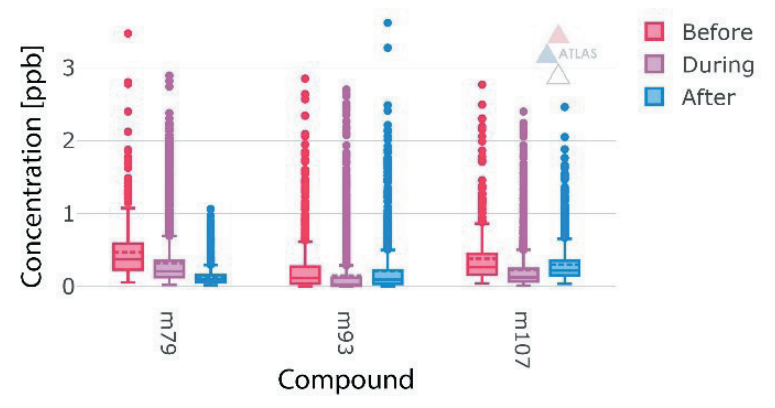

Figure 4 - BTEX box plots.
The daily and weekly variations in BTEX levels are shown in Figure 6. Daily variations (pronounced peaks early in the morning, late afternoon, and evening) indicated the expected distribution of VOC concentrations governed by meteorological parameters, photochemical processes, planetary boundary layer height evolution, and human activities in all three examined periods.

In contrast to the relatively stable daily dynamics, BTEX weekly variations changed over time. Before the lockdown, the highest BTEX levels were registered on Tuesday and Wednesday. During the lockdown, concentration peaks were displaced to Friday, while after the lockdown period, BTEX levels peaked on weekend.

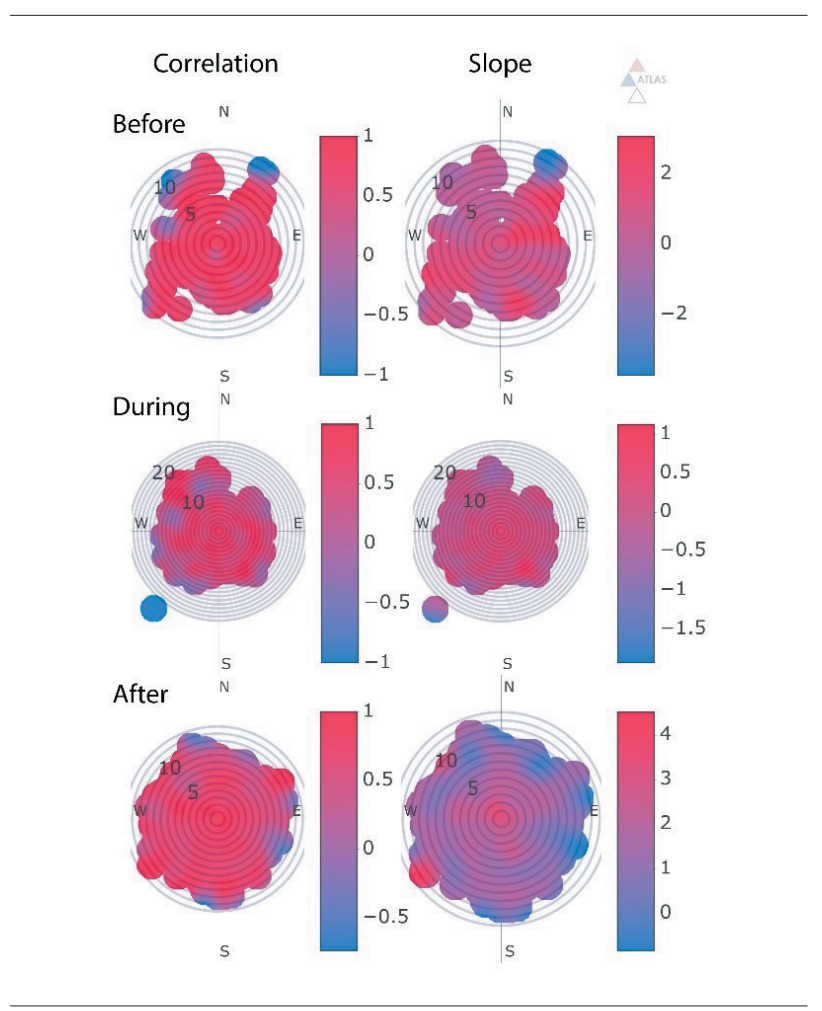

Figure 5 - Toluene and benzene correlation and slope dependency on wind parameters.

After the restrictive measures have ended, the pronounced BTEX peaks on weekends might be associated with travel, recreation activities, and staying outdoors, although based on the analysis of the time series (Figure 1), it is clear that increased human activities after the lockdown did not induce an increase in benzene concentrations, neither reestablishment of the correlations between BTEX compounds and human activity (Figure 2). 


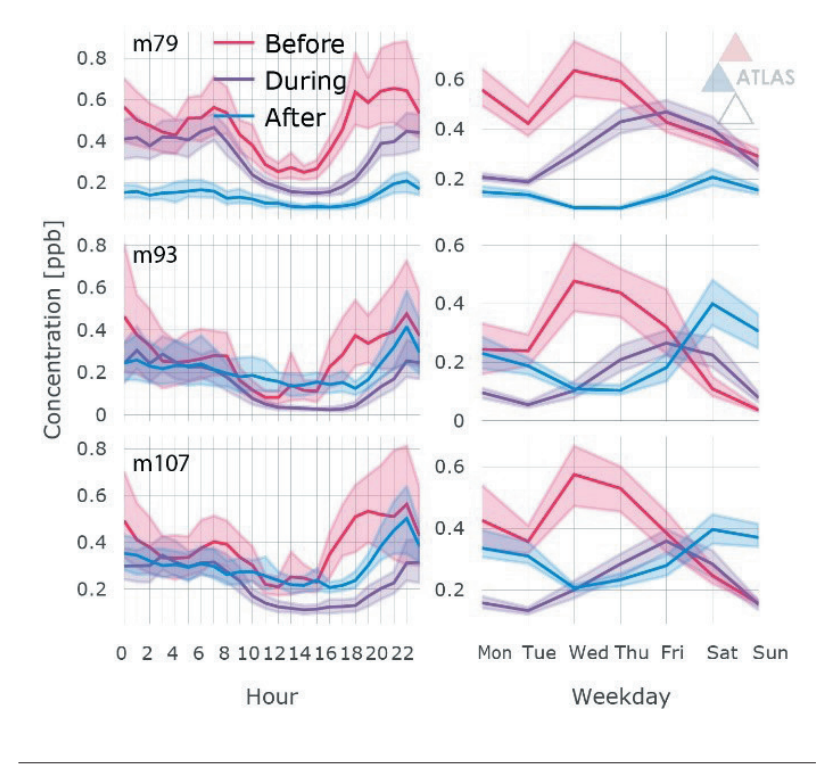

Figure 6 - BTEX diurnal and weekday variations.

As this type of analysis cannot indicate the main causes for the observed weekly variations in BTEX levels, it is necessary to approach more complex and precise analyzes.

\section{CONCLUSION}

While in the period before the introduction of the state of emergency and reduced human mobility, benzene and toluene levels exhibited no correlation, during and after the lockdown period strong correlations were observed between BTEX compounds, but no significant correlations between BTEX levels and human mobility were detected. An increase of human activities after the lockdown did not induce an increase in benzene concentrations, neither reestablishment of the correlations between BTEX compounds and human activities.

\section{ACKNOWLEDGEMENTS}

The authors acknowledge funding provided by the Institute of Physics Belgrade, through the grant by the Ministry of Education, Science and Technological Development of the Republic of Serbia and the Science Fund of the Republic of Serbia \#GRANT No. 6524105, AI-ATLAS,

\section{REFERENCES}

[1] J. Calvin, A. Hansell, K. Adams i J. Gulliver, „Changes in air quality during COVID-19 'lockdown'in the United Kingdom," Environmental Pollution, t. 272, p. 116011, 2021.

[2] S. Mor, S. Kumar, T. Singh, S. Dogra, V. Pandey i K. Ravindra, „Impact of COVID-19 lockdown on air quality in Chandigarh, India: understanding the emission sources during controlled anthropogenic activities," Chemosphere, t. 263, p. 127978, 2021.

[3] M. F. Sari i F. Esen, „Effect of COVID-19 on PM10 and $\mathrm{SO} 2$ concentrations in Turkey, "Environmental Forensics, pp. 1-10, 2021.

[4] A. Pakkattil, M. Muhsin i R. Varma, „COVID-19 lockdown: Effects on selected volatile organic compound (VOC) emissions over the major Indian metro cities,"Urban Climate, t. 37, p. 100838, 2021.

[5] A. Kerimray, N. Baimatova, O. Ibragimova, B. Bukenov, B. Kenessov, P. Plotitsyn i F. Karaca, „Assessing air quality changes in large cities during COVID-19 lockdowns: The impacts of traffic-free urban conditions in Almaty, Kazakhstan, "Science of the Total Environment, t. 730, p. 139179, 2020.

[6] W. Lindinger, A. Hansel and A. Jordan, "On-line monitoring of volatile organic compounds at pptv levels by means of proton-transfer-reaction mass spectrometry (PTR-MS) medical applications, food control and environmental research," International Journal of Mass Spectrometry and Ion Processes, vol. 173, no. 3, pp. 191-241, 1998.

[7] A. Stojić, S. Stanišić Stojić, Z. Mijić, A. Šoštarić i S. Rajšić, „Spatio-temporal distribution of VOC emissions in urban area based on receptor modeling," Atmospheric Environment, t. 106, pp. 71-79, 2015.

[8] R. Taipale, T. M. Ruuskanen, J. Rinne, M. K. Kajos, H. Hakola, T. Pohja i M. Kulmala, „Quantitative long-term measurements of VOC concentrations by PTR-MS-measurement, calibration, and volume mixing ratio calculation methods," Atmospheric Chemistry and Physics, t. 8, br. 22, pp. 6681-6698, 2008.

[9] S. Grange, A. Lewis i D. Carslaw, „Source apportionment advances using polar plots of bivariate correlation and regression statistics," Atmospheric Environment, t. 145, pp. 128-134, 2016. 